Article

\title{
A Probabilistic Model for Optimal Bridge Inspection Interval
}

\author{
Mohammad Ilbeigi *(D) and Bhushan Pawar \\ Department of Civil, Environmental, and Ocean Engineering (CEOE), Stevens Institute of Technology, \\ Hoboken, NJ 07030,USA; bpawar@stevens.edu \\ * Correspondence: milbeigi@stevens.edu
}

Received: 3 May 2020; Accepted: 4 June 2020; Published: 6 June 2020

\begin{abstract}
The US Department of Transportation and Federal Highway Administration require routine inspections to monitor bridge deterioration. Typically, bridge inspections are conducted every 24 months. This timeframe was determined solely based on engineering judgment. The objective of this study is to develop probabilistic models to forecast bridge deterioration and statistically determine the optimal inspection intervals. A two-dimensional Markov process model that considers the current condition of a bridge, and number of years that the bridge has been in that condition, is created to predict future bridge conditions based on historical data. Using the forecasting model, a statistical process is developed to determine the optimal inspection intervals. The proposed methodology in this study is implemented, utilizing a dataset consisting of information about deterioration conditions of more than 17,500 bridges in the state of New York from 1992 to 2018. The outcomes of the statistical analysis indicate that the typical 24-month inspection interval is considerably pessimistic, and not necessary for all bridges currently in condition 5 or higher. However, the 24-month interval is too optimistic and risky for bridges currently in condition 4 or lower. The outcomes of this study help bridge owners and transportation agencies assign maintenance resources efficiently, and invest the millions of dollars currently allocated for unnecessary inspections in much-needed infrastructure development projects.
\end{abstract}

Keywords: bridge condition; inspection interval; probabilistic models; Markov process

\section{Introduction}

The United States has more than 615,000 bridges, which are critical components of the US transportation system. The National Bridge Inspection Standard (NBIS) developed by the Federal Highway Administration (FHWA) requires regular and periodic comprehensive inspection of these bridges, that addresses all elements of a bridge, including substructure and superstructure. The typical inspection interval is 24 months, but can be extended to 48 months for short-span bridges (typically less than $150 \mathrm{ft}$ ) in good condition with low average daily traffic (ADT) [1]. For certain bridges with existing damage, a shorter inspection interval may be requested by owners. However, the majority of the bridges in the US are inspected based on the 24-month interval. Based on the NBIS procedure, whenever a bridge is inspected, a rating condition from 1 to 9 is assigned to the bridge. Table 1 describes the bridge condition ratings by the NBIS.

The 24-month routine inspection interval was determined by the FHWA in the 1970s solely based on engineering judgment, regardless of the current condition of the bridges. This uniform interval approach has resulted in a very costly and inefficient process [2-4]. Many bridges in proper condition do not need to be inspected every 24 months. On the other hand, some bridges with a high deterioration rate may need a shorter inspection period. The FHWA's need to be especially conservative was understandable in the 1970s, when it developed the NBIS and initiated the bridge 
inspection process. Today, however, the availability of historical records of bridge conditions allow the creation of a systematic process based on historical deterioration data to empirically determine the inspection interval.

Table 1. National Bridge Inspection Standard (NBIS) bridge condition rating.

\begin{tabular}{cc}
\hline Condition Rating & Description \\
\hline 9 & Excellent Condition \\
8 & Very Good Condition \\
7 & Good Condition \\
6 & Satisfactory Condition \\
5 & Fair Condition \\
4 & Poor Condition \\
3 & Serious Condition \\
2 & Critical Condition \\
1 & Imminent Failure Condition \\
\hline
\end{tabular}

Analyzing bridge deterioration and bridge facility management has been a popular research topic during the recent decade. These studies can be categorized into two groups. The first group focuses on modeling and analyzing bridge deterioration rates. For example, Madanat et al. [5] developed a probit model with a random-effect specification for bridge-deck deterioration. Miyamoto et al. [6] proposed a biquadratic deterioration curve for concrete bridge members. Bolukbasi et al. [7] tried to analyze the relationship between bridge condition rating and bridge age by simply fitting a third-degree polynomial line, and compared deterioration rates for decks, superstructures, and substructures. Agrawal et al. [8] described an approach based on the Weibull distribution to create bridge element deterioration curves. Tolliver and $\mathrm{Lu}$ [9] analyzed the relationship between bridge deterioration rates and age; they observed that the relationship between these two factors is linear for bridges less than 65 years old, after which they have a polynomial relationship. Ghonima [10] created a binary logistic regression to analyze the effects of bridge characteristics such as ADT, age, deck area, and number of lanes on deterioration rate. A fair number of studies in this group used a Markovian process to analyze bridge deterioration rates. For example, Morcous [11] investigated the validity of Markov chain basic assumptions for the infrastructure deterioration process. Cesare et al. [12] discussed two approaches to estimate Markov transition matrices for different bridge components with limited historical data. Morcous et al. [13] used a genetic algorithm to propose a decision support tool that combines environmental factors with bridge deterioration Markov models to improve the applicability of the models. Wellalage et al. [14] presented a Metropolis-Hasting algorithm for a Markov-based Monte Carlo simulation model that is calibrated for railway bridge elements. Ranjith et al. [15] used Markov chains to model deterioration of timber bridge elements in Australia. Ng and Moses [16] developed a semi-Markov stochastic model that uses a holding time distribution to explain the duration of time that a bridge stays in one condition. Masovic and Hajdin [17] proposed an expectation maximization algorithm to estimate a Markov transition matrix when bridge condition historical data was not recorded at a uniform interval. Zambon et al. [18] used carbonation-induced corrosion models to explain sojourn time in a semi-Markov model for concrete bridges. Fang and Sun [19] integrated a Weibull distribution into a semi-Markov model to explain deterioration of concrete urban bridges in Shanghai.

A major limitation in the previous studies that used Markovian process to analyze and model bridge deteriorations is related to the memoryless assumption of the Markov process. In other words, the previous models only considered the current condition of a bridge to predict its future condition. However, as discussed in more detail in Section 3, this assumption may not be valid for bridge deterioration modeling. Previous conditions of a bridge may have useful information that should be considered in deterioration analyses.

The second group of previous studies aimed to address bridge facility management problems. For example, Zhang et al. [20] developed a discrete event simulation to find an optimal combination 
of resources in bridge-deck rehabilitation projects. Nasrollahi and Washer [2] conducted a statistical analysis to find the best conventional distribution that describes the distribution of the time that a bridge may stay in one specific condition. The fitted distributions for different condition ratings showed that, on average, bridges stay in higher conditions for longer periods, and the 24-month maximum inspection interval is pessimistic. Washer et al. [4] developed a framework for risk-based bridge inspection that identifies bridges for which inspection intervals shorter, or longer, than 24 months are more appropriate. Their proposed framework uses a qualitative approach based on a simple risk matrix. Washer et al. [21] conducted two case studies to present the implementation of their proposed framework. Ghodoosi et al. [22] developed a genetic algorithm model to optimize lifecycle costs of bridge utilization. Ilbeigi and Ebrahimi-Meimand [23] created an ordinal regression model to forecast future bridge conditions, based on bridge characteristics such as structural materials, structure systems, age, and average daily traffic. Although these studies provide useful insights and information about bridge facility management, little is known about a systematic and quantitative approach to empirically determine inspection intervals based on historical data. This gap in knowledge makes it difficult to use facility management resources efficiently.

The objective of this study is to create and test the applicability of a novel probabilistic model to determine inspection intervals based on historical inspection data. The inspection records of more than 17,500 bridges in the state of New York from 1992 to 2018 were collected, and a two-dimensional Markov process model that takes into account both the current bridge condition and the number of years that the bridge has been in that condition is created to statistically predict future bridge conditions. A probabilistic process based on organizations' (i.e., bridge owners) risk-tolerance is then conducted to determine the optimal inspection intervals. The outcomes of this study will help decision makers quantitatively determine inspection intervals, to use bridge inspection resources efficiently and save millions of dollars that can be invested in other infrastructure development projects. The remainder of this paper is structured as follows: first, the National Bridge Inventory (NBI) dataset is briefly introduced. Next, the research methodology and steps conducted in this study are described. The proposed methodology is then applied to the New York NBI dataset to statistically determine the optimized inspection intervals and evaluate the performance of the proposed methodology. Finally, the results are presented, and future works are recommended.

\section{NBI Dataset}

The NBI is a publicly available dataset published by the FHWA, consisting of detailed information including bridge condition values (Table 1) for all bridges in the US. Currently, the recorded data from 1992 to 2018 are available [24]. With more than 17,500 bridges, New York is one of the states with the highest number of bridges in the country. Although the FHWA requires bridge inspection at least every 24 months, the State of New York inspects its bridges annually. Therefore, the NBI dataset consists of 27 observations for each bridge from 1992 to 2018. Figure 1 shows the percentage of each condition level in 2018.

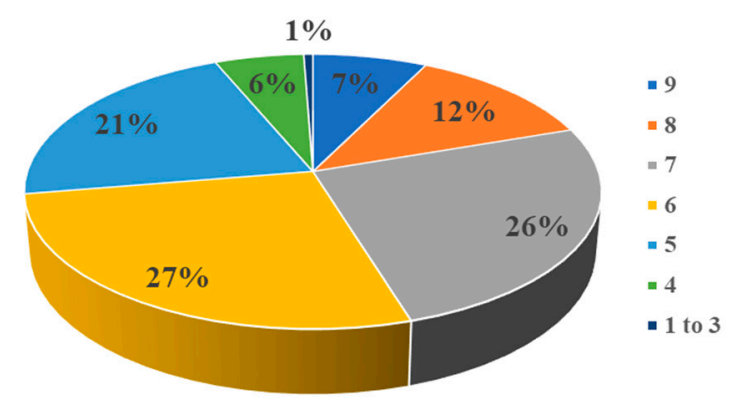

Figure 1. Percentage of each condition level in 2018. 
Figure 2 shows the changes in the percentage of each condition value through time from 1992 to 2018. Overall, there is a considerable downward trend in the proportion of condition groups 1 to 4 from 1992 to 2001. From 2001, the proportions of all conditions have been relatively stable.

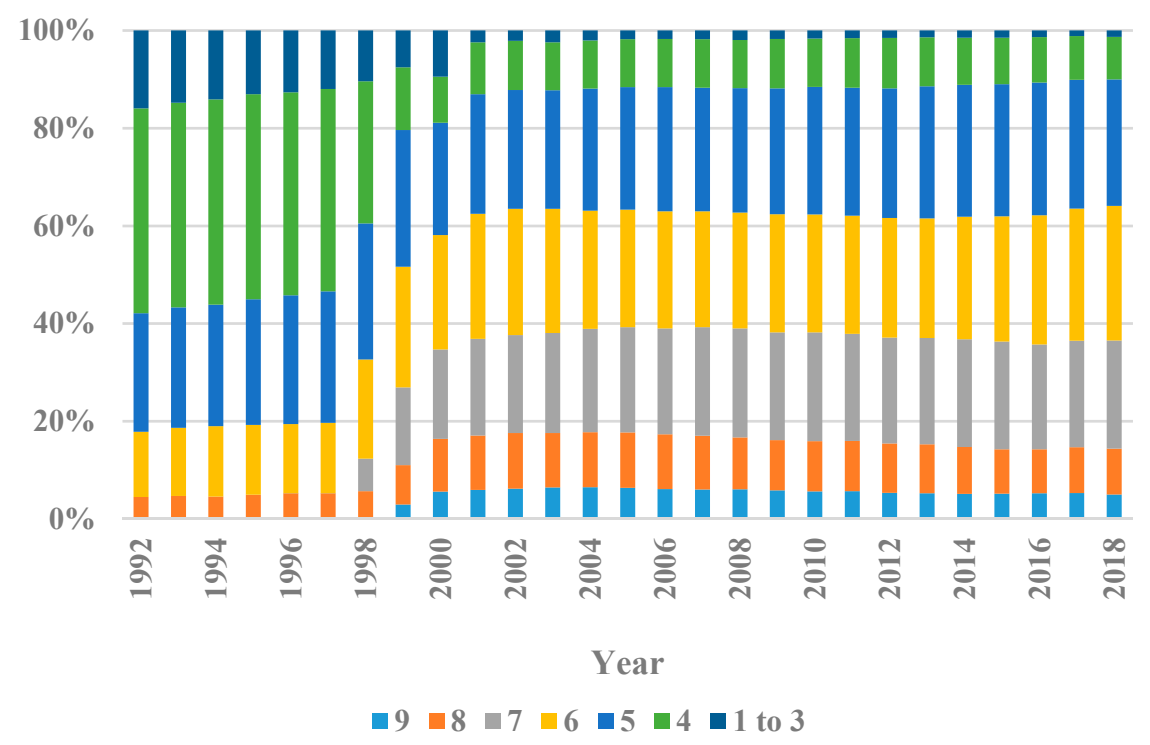

Figure 2. Percentage of each condition value from 1992 to 2018.

\section{Data Preprocessing and Cleaning}

Because a condition rating of 3 indicates a serious problem, bridges with a condition rating of 3 or less need immediate attention and typically undergo major rehabilitation [2]. Therefore, in this study, these three ratings were combined to develop the caution condition which indicates a bridge in need of particular attention. During the inspection process, it is critical to predict whether the bridge will transition to this condition in the near future.

Deterioration of a bridge results in a transition from a higher condition rating to a lower condition rating. Therefore, typically, a bridge stays in its current condition or transitions to a lower condition rating, unless it undergoes rehabilitation or there is an error in data collection. Because the focus of this study is deterioration through time, upward transitions from lower ratings to higher ratings were removed from the dataset. Furthermore, miscoded ratings with a value of 0 or $\mathrm{N}$ were removed from the dataset as well. These data preprocessing operations were suggested by previous studies, such as that by $[2,25]$. The proposed data preprocessing and cleaning operation led to removal of less than $10 \%$ of the original data.

\section{Research Methodology}

Deterioration of a bridge through its lifecycle can be analyzed by a discrete function that models the transition from higher condition rates (e.g., 9, when the bridge is newly constructed or recently maintained) to lower condition ratings. These transitions can be modeled using a Markov chain process [12-16]. The classic Markov chain model is a memoryless stochastic process that predicts transitions of a variable among discrete states solely based on its current state.

$$
\operatorname{Pr}\left(X_{n+1}=x \mid X_{1}=x_{1}, X_{2}=x_{2}, X_{3}=x_{3}, \ldots, X_{n}=x_{n}\right)=\operatorname{Pr}\left(X_{n+1}=x \mid X_{n}=x_{n}\right)
$$

The main component of a Markov process is the transition matrix that describes the probability of a transition from one state to another. The elements of the transition matrix are calculated using the historical data, as follows:

$$
P \_i j=n \_i j / n \_i
$$


where

$P_{i j}$ is the probability of a transition from state $i$ to state $j$;

$n_{i j}$ is the total number of transitions from state $i$ to state $j$ within a given time period;

$n_{i}$ is the total number of bridges in state $i$ before transition.

Using the transition matrix, future states can be predicted as follows:

$$
S(t+n)=S(t) \times P^{n}
$$

where

$S(t)$ is an array that shows the state at time $t$;

$S(t+n)$ is an array that shows the state at time $t+n$ :

$P$ is the transition matrix.

More detailed information about the Markov process was reviewed in [26].

The classic Markov process is a memoryless model that assumes the future state depends only on the current condition. However, in the case that the historical data has useful information for predicting future states, the memoryless assumption of the classic Markov process may not be valid. In the case of bridge condition assessment, the previous conditions of a bridge may have useful information that should be considered in the prediction process. For example, a bridge that just transitioned from condition 7 to condition 6 may have a higher chance of staying in condition 6 in the next year, compared with a bridge that has been in condition 6 for several years, which may have a higher chance of deteriorating to a lower condition during the next year. To address this issue, in this study, a two-dimensional Markov model is created. The model takes two variables to define a Markov state: (1) the bridge current condition; and (2) the number of years that the bridge has been in that condition continuously. Therefore, each element of $S(t)$ is represented by a vector as follows:

$$
E(t)=\left[\begin{array}{l}
C_{t} \\
Y_{t}
\end{array}\right]
$$

where

$C_{t}$ is the bridge condition at time $t$;

$Y_{t}$ is the number of years that the bridge has been in condition $C_{t}$ by time $t$.

For example, if a bridge has been in condition 5 for the last 3 years, its state is $\left[\begin{array}{l}5 \\ 3\end{array}\right]$. During the next year, this bridge may stay in condition 5 , that means a transition from state $\left[\begin{array}{l}5 \\ 3\end{array}\right]$ to state $\left[\begin{array}{l}5 \\ 4\end{array}\right]$, or it may deteriorate to condition 4 , that results in a transition from state $\left[\begin{array}{l}5 \\ 3\end{array}\right]$ to state $\left[\begin{array}{l}4 \\ 1\end{array}\right]$, or it may also deteriorate directly to the caution condition (i.e., condition 3 or lower), that indicates a transition from state $\left[\begin{array}{l}5 \\ 3\end{array}\right]$ to state $\left[\begin{array}{c}3-1 \\ 1\end{array}\right]$.

In this study, the proposed two-dimensional Markov process is used to create a probabilistic forecasting model for the bridge deterioration process. The forecasting model is then used to statistically determine the optimal bridge inspection intervals. In summary, the following steps are taken:

- Preparing the NBI data to be used in the proposed two-dimensional Markov model

- Calculating transition probabilities, creating the transition matrix using historical data from 1992 to 2017, and developing the two-dimensional Markov model

- Evaluating the prediction power of the developed two-dimensional Markov model

- Predicting future bridge conditions for the next $n$ years

- Selecting a risk tolerance for the bridge owner 
- Determining the inspection intervals based on the predicted transition probabilities and the risk tolerance

Figure 3 shows the summary of the steps conducted in this study to develop the prediction model and statistical process to determine the optimal inspection interval.

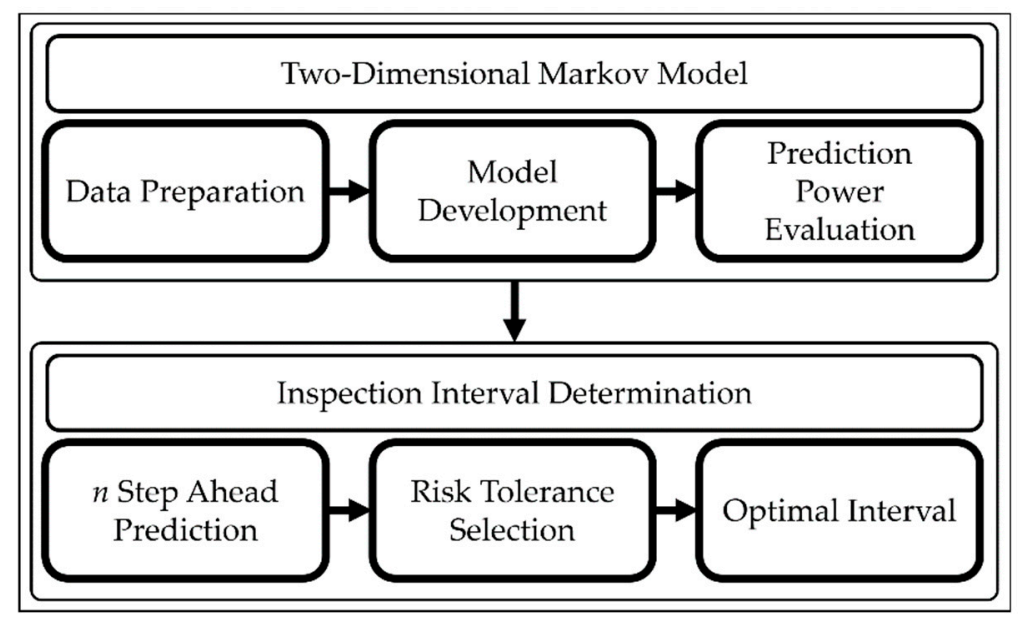

Figure 3. Steps conducted in this study.

\section{Analysis of Bridge Conditions in the State of New York}

The New York NBI data from 1992 to 2017 was analyzed to identify the states (i.e., bridge condition and number of years that the bridge has been in that condition) and calculate the transition probabilities. Overall, 150 possible states were observed in the historical data. Therefore, the transition matrix is 150 by 150 . However, a significant number of elements in the matrix are zero, due to the logically impossible transitions between some states. For example, a direct transition from $\left[\begin{array}{l}5 \\ 3\end{array}\right]$ to $\left[\begin{array}{l}4 \\ 2\end{array}\right]$ is not possible. Because even if a bridge that has been in condition 5 for 3 years deteriorates to condition 4 , the new state is $\left[\begin{array}{l}4 \\ 1\end{array}\right]$. More than 372,000 transitions were extracted from the dataset to calculate the transition probabilities. Considering the size of the transition matrix, it is not feasible to present the entire matrix in this paper. However, Table 2 presents a small portion of the matrix that shows possible transition probabilities for a bridge currently in state $\left[\begin{array}{l}9 \\ 4\end{array}\right]$. The table indicates that if a bridge has been in condition 9 during the last 4 years, there is a $70.41 \%$ chance that the bridge will stay in condition 9 until the next year (i.e., transition from state $\left[\begin{array}{l}9 \\ 4\end{array}\right]$ to state $\left[\begin{array}{l}9 \\ 5\end{array}\right]$ ). The probabilities that the bridge condition change to conditions $8,7,6,5,4$, and 3 or lower (i.e., caution condition) are also $21.07 \%, 6.59 \%, 1.03 \%, 0.75 \%, 0.09 \%$, and $0.05 \%$, respectively.

Table 2. Transition probabilities for a bridge in state $\left[\begin{array}{l}9 \\ 4\end{array}\right]$.

\begin{tabular}{|c|c|c|c|c|c|c|c|}
\hline State & $\left.\begin{array}{l}9 \\
5\end{array}\right]$ & $\left.\begin{array}{l}8 \\
1\end{array}\right]$ & {$\left[\begin{array}{l}7 \\
1\end{array}\right]$} & {$\left[\begin{array}{l}6 \\
1\end{array}\right]$} & {$\left[\begin{array}{l}5 \\
1\end{array}\right]$} & {$\left[\begin{array}{l}4 \\
1\end{array}\right]$} & {$\left[\begin{array}{c}3-1 \\
1\end{array}\right.$} \\
\hline $\begin{array}{l}9 \\
4\end{array}$ & $70.41 \%$ & $21.07 \%$ & $6.59 \%$ & $1.03 \%$ & $0.75 \%$ & $0.09 \%$ & $0.05 \%$ \\
\hline
\end{tabular}

Now, the prediction ability of the proposed two-dimensional Markov process should be tested to validate the model. To evaluate the performance of the model, the expected number of bridges in 
each Markov state in 2018 is predicted, using the developed model based on the available data in 2017 as follow:

$$
S(2018)=S(2017) \times P^{1}
$$

An array that contains the actual number of bridges in each Markov state in 2017, $S(2017)$, is the input; an array that shows the predicted number of bridges in each Markov state in 2018, $S(2018)$, is the output; and an array that consists of actual number of bridges in each Markov state in 2018 is the benchmark to evaluate the prediction power of the model. If the predicted numbers of bridges in each state are close to the actual numbers, the model has a reliable prediction power. Considering that $S(t)$ (i.e., array of number of bridges in each state at time $t$ ) is a relatively long vector that contains 150 elements (i.e., Markov states), it is not feasible to present the entire vectors for 2017 and 2018 in this manuscript. However, Table 3 shows a small portion of those vectors for the sake of explanation. Table 3 shows the actual number of bridges in states $\left[\begin{array}{l}7 \\ 1\end{array}\right]$ to $\left[\begin{array}{l}7 \\ 5\end{array}\right]$ in 2017, their predicted values in 2018 , and their actual values in 2018. The absolute percentage error of the prediction process for the entire states in 2018 is $2.94 \%$ and was calculated as follows:

$$
A P E=\frac{\sum_{i=1}^{n}\left|A_{i}-F_{i}\right|}{\sum_{i=1}^{n} A_{i}}
$$

where

$A_{i}$ is the actual value;

$F_{i}$ is the forecast value;

$n$ is the number of states that is 150 in this analysis.

Table 3. Actual and predicted number of bridges in states $\left[\begin{array}{l}7 \\ 1\end{array}\right]$ to $\left[\begin{array}{l}7 \\ 5\end{array}\right]$.

\begin{tabular}{cccccc}
\hline State & {$\left[\begin{array}{l}\mathbf{7} \\
\mathbf{1}\end{array}\right]$} & {$\left[\begin{array}{l}\mathbf{7} \\
\mathbf{2}\end{array}\right]$} & {$\left[\begin{array}{l}\mathbf{7} \\
\mathbf{3}\end{array}\right]$} & {$\left[\begin{array}{l}\mathbf{7} \\
\mathbf{4}\end{array}\right]$} & {$\left[\begin{array}{l}\mathbf{7} \\
\mathbf{5}\end{array}\right]$} \\
\hline Actual Number of Bridges in 2017 & 434 & 260 & 265 & 281 & 253 \\
Predicted Number of Bridges for 2018 & 200 & 427 & 211 & 262 & 238 \\
Actual Number of Bridges in 2018 & 207 & 428 & 214 & 265 & 242 \\
\hline
\end{tabular}

Determining Inspection Intervals

To determine the optimal inspection interval for a bridge in a specific state, the forecasting model is used to predict its future possible states for the next $n$ years. The outcomes show the probability of transition from the origin state to other states at the end of each year. For example, Table 4 shows the transition probabilities for a bridge that has been in condition 5 for two years (i.e., state $\left[\begin{array}{l}5 \\ 2\end{array}\right]$ ), during the next 6 years. For the next year, the table indicates that the bridge may stay in condition 5 (i.e., transition to state $\left[\begin{array}{l}5 \\ 3\end{array}\right]$ ) with $89.6 \%$ probability, and may deteriorate to condition 4 (i.e., transition to state $\left[\begin{array}{l}4 \\ 1\end{array}\right]$ ), or condition 3 or lower (i.e., transition to state $\left[\begin{array}{c}3-1 \\ 1\end{array}\right]$ ), with $9.6 \%$ and $0.8 \%$, respectively. After two years, the chances that the bridge is in states $\left[\begin{array}{l}5 \\ 4\end{array}\right],\left[\begin{array}{l}4 \\ 1\end{array}\right],\left[\begin{array}{l}4 \\ 2\end{array}\right]$, and $\left[\begin{array}{c}3-1 \\ 1\end{array}\right]$ are $86.4 \%, 2.9 \%$, $9.3 \%$, and $1.4 \%$, respectively.

Table 4 indicates that the likelihood that a bridge in state $\left[\begin{array}{l}5 \\ 2\end{array}\right]$ will transition to the caution condition (i.e., condition 3 or below) after five and six years are $4.4 \%$ and $5.27 \%$, respectively. Therefore, if the risk tolerance of the bridge owner is $5 \%$, the optimal inspection interval is 5 years, which is the longest duration that has a probability of transition to the caution state that is less than the risk tolerance 
(i.e., $5 \%$ ). If the risk tolerance was $3 \%$, for example, the optimized inspection interval would be 3 years. The optimal inspection interval, based on the bridge owner's risk tolerance, can be calculated for all existing 150 states in the dataset. Table 5 shows the optimal intervals for bridges currently in some of the most common states in the dataset, based on a $5 \%$ risk tolerance. The results indicate that, for example, if a bridge has been in condition 9 during the last four years, the chance that it deteriorates to the caution condition during the next 20 years is less than $5 \%$.

Table 4. Transition probability for a bridge currently in $\left[\begin{array}{l}5 \\ 2\end{array}\right]$.

\begin{tabular}{|c|c|c|c|c|c|c|c|}
\hline \multirow[b]{2}{*}{ State } & \multicolumn{7}{|c|}{ Transition Probability } \\
\hline & $\begin{array}{c}\text { Current } \\
\text { Year }\end{array}$ & $\begin{array}{c}\text { After } 1 \\
\text { Year }\end{array}$ & $\begin{array}{c}\text { After } 2 \\
\text { Years }\end{array}$ & $\begin{array}{c}\text { After } 3 \\
\text { Years }\end{array}$ & $\begin{array}{c}\text { After } 4 \\
\text { Years }\end{array}$ & $\begin{array}{c}\text { After } 5 \\
\text { Years }\end{array}$ & $\begin{array}{c}\text { After } 6 \\
\text { Years }\end{array}$ \\
\hline $\begin{array}{l}5 \\
2\end{array}$ & $100 \%$ & - & - & - & - & - & - \\
\hline $\begin{array}{l}5 \\
3\end{array}$ & - & $89.6 \%$ & - & - & - & - & - \\
\hline $\begin{array}{l}5 \\
4\end{array}$ & - & - & $86.4 \%$ & - & - & - & - \\
\hline $\begin{array}{l}5 \\
5\end{array}$ & - & - & - & $78.9 \%$ & - & - & - \\
\hline $\begin{array}{l}5 \\
6\end{array}$ & - & - & - & - & $76.1 \%$ & - & - \\
\hline $\begin{array}{l}5 \\
7\end{array}$ & - & - & - & - & - & $71.4 \%$ & - \\
\hline $\begin{array}{l}5 \\
8\end{array}$ & - & - & - & - & - & - & $70.2 \%$ \\
\hline $\begin{array}{l}4 \\
1\end{array}$ & - & $9.6 \%$ & $2.9 \%$ & $6.8 \%$ & $2.5 \%$ & $4.3 \%$ & $0.9 \%$ \\
\hline $\begin{array}{l}4 \\
2\end{array}$ & - & - & $9.3 \%$ & $2.8 \%$ & $6.6 \%$ & $2.5 \%$ & $4.1 \%$ \\
\hline $\begin{array}{l}4 \\
3\end{array}$ & - & - & - & $9.0 \%$ & $2.7 \%$ & $6.3 \%$ & $2.4 \%$ \\
\hline $\begin{array}{l}4 \\
4\end{array}$ & - & - & - & - & $8.8 \%$ & $2.7 \%$ & $6.2 \%$ \\
\hline $\begin{array}{l}4 \\
5\end{array}$ & - & - & - & - & - & $8.5 \%$ & $2.6 \%$ \\
\hline $\begin{array}{l}4 \\
6\end{array}$ & - & - & - & - & - & - & $8.3 \%$ \\
\hline $\begin{array}{c}3-1 \\
1\end{array}$ & - & $0.8 \%$ & $1.4 \%$ & $2.5 \%$ & $3.3 \%$ & $4.4 \%$ & $5.3 \%$ \\
\hline
\end{tabular}

Table 5 shows why the 24-month routine inspection interval may not be a proper facility management strategy. On the one hand, the outcomes presented in Table 5 indicate that with a $5 \%$ risk tolerance, the 24-month inspection interval is too optimistic for bridges in condition 4, because there is a more than $5 \%$ chance that they may transition to the caution condition (i.e., condition 3 or lower) in less than two years. On the other hand, for bridges currently in condition 5 or higher, the 24-month strategy is too pessimistic. If a bridge has been in condition 6 for 2 years, for example, the probability that it deteriorates to the caution condition during the next 10 years is less than $5 \%$. Therefore, the bridge owners may decide to extend the inspection interval. 
Table 5. Optimal inspection intervals for 5\% risk tolerance.

\begin{tabular}{cc}
\hline Current State & Optimal Inspection Interval \\
\hline$\left[\begin{array}{l}9 \\
4\end{array}\right]$ & 20 Years \\
{$\left[\begin{array}{l}8 \\
2\end{array}\right]$} & 17 Years \\
{$\left[\begin{array}{l}7 \\
2\end{array}\right]$} & 15 Years \\
{$\left[\begin{array}{l}6 \\
2\end{array}\right]$} & \\
{$\left[\begin{array}{l}5 \\
2\end{array}\right]$} & 10 Years \\
{$\left[\begin{array}{l}4 \\
2\end{array}\right]$} & 5 Years \\
{$\left[\begin{array}{l}4 \\
7\end{array}\right]$} & 1 Year \\
\hline
\end{tabular}

\section{Conclusions and Future Works}

A two-dimensional Markov model that considers both the current condition of a bridge, and the number of years that the bridge has been in that condition, was created to predict future bridge conditions based on historical data. The model was applied on a dataset consisting of information about more than 17,500 bridges in the state of New York from 1992 to 2018. The forecasting results indicate that the model can predict future conditions accurately with less than $3 \%$ error.

Using the proposed Markov forecasting model, a statistical process to determine optimal inspection intervals was developed. The statistical process is flexible, and can be adjusted based on the risk tolerance and the threshold for caution state. In this study, the empirical analysis was conducted based on a 5\% risk tolerance, and condition 3 was considered the threshold for the caution state. However, other risk tolerances and thresholds could be used as well.

The results of this study indicate that the typical 24-month inspection interval is considerably pessimistic, and not necessary for all bridges currently in condition 5 or higher. However, a 24-month interval is too optimistic, and risky for bridges currently in condition 4 or lower. The primary contribution of this study to the body of knowledge is its creation of a novel two-dimensional Markov model to probabilistically forecast bridge deterioration, and a systematic process to statistically determine the optimal inspection intervals based on the bridge owner's risk tolerance. The outcomes of this study help bridge owners and transportation agencies assign maintenance resources efficiently, and invest the millions of dollars currently funding unnecessary inspections into much-needed infrastructure development projects. However, it should be noted that further studies are needed to design reliable and optimal bridge inspection policies that consider different aspects of the problem. Particularly, analyzing impacts of unprecedented environmental factors, including climate change and natural extreme events (i.e., hurricane, earthquake, and flood) on deterioration rate of a bridge is critical to develop a comprehensive set of maintenance and inspection policies. Furthermore, analyzing the impacts of bridge characteristics such as design, material, age, deck area, and ADT on deterioration rates, and creating causal models that predict future bridge conditions based on their main characteristics, are vital to enable transportation agencies to extend their routine inspection intervals or adopt more flexible inspection procedures safely. In addition, cost-based inspection analyses that determine the optimal bridge inspection intervals with regards to minimizing the maintenance cost of a bridge, are a key factor in using resources efficiently. 
preparation, M.I.; writing—review and editing, M.I.; visualization, B.P.; supervision, M.I.; project administration, M.I. All authors have read and agreed to the published version of the manuscript.

Funding: This research received no external funding.

Conflicts of Interest: The authors declare no conflict of interest.

\section{References}

1. Federal Highway Administration (FHWA). Revisions to the National Bridge Inspection Standards (NBIS); Tech. Advisory 5140.21: Washington, DC, USA, 1988.

2. Nasrollahi, M.; Washer, G. Estimating inspection intervals for bridges based on statistical analysis of national bridge inventory data. J. Bridge Eng. 2014, 20, 04014104. [CrossRef]

3. Reising, R. Risk-based Bridge Inspection Practices. Master's Thesis, Purdue University, West Lafayette, IN, USA, 2014.

4. Washer, G.; Connor, R.; Nasrollahi, M.; Reising, R. Verification of the framework for risk-based bridge inspection. J. Bridge Eng. 2016, 21, 04015078. [CrossRef]

5. Madanat, S.; Ibrahim, W.H.W. Poisson regression models of infrastructure transition probabilities. J. Transp. Eng. 1995, 121, 267-272. [CrossRef]

6. Miyamoto, A.; Kawamura, K.; Nakamura, H. Bridge management system and maintenance optimization for existing bridges. Comput. Aided Civ. Infrastruct. Eng. 2000, 15, 45-55. [CrossRef]

7. Bolukbasi, M.; Mohammadi, J.; Arditi, D. Estimating the future condition of highway bridge components using national bridge inventory data. Pract. Period. Struct. Des. Constr. 2004, 9, 16-25. [CrossRef]

8. Agrawal, A.K.; Kawaguchi, A.; Chen, Z. Deterioration rates of typical bridge elements in New York. J. Bridge Eng. 2010, 15, 419-429. [CrossRef]

9. Tolliver, D.; Lu, P. Analysis of bridge deterioration rates: A case study of the northern plains region. J. Transp. Res. Forum 2012, 50, 87-100. [CrossRef]

10. Ghonima, O. Statistical Modeling of United States Highway Concrete Bridge Decks. Ph.D. Thesis, University of Delaware, Newark, DE, USA, 2017.

11. Morcous, G. Performance prediction of bridge deck systems using Markov chains. J. Perform. Constr. Facil. 2006, 20, 146-155. [CrossRef]

12. Cesare, M.A.; Santamarina, C.; Turkstra, C.; Vanmarcke, E.H. Modeling bridge deterioration with Markov chains. J. Transp. Eng. 1992, 118, 820-833. [CrossRef]

13. Morcous, G.; Lounis, Z.; Mirza, M.S. Identification of environmental categories for Markovian deterioration models of bridge decks. J. Bridge Eng. 2003, 8, 353-361. [CrossRef]

14. Wellalage, N.K.W.; Zhang, T.; Dwight, R. Calibrating Markov chain-based deterioration models for predicting future conditions of railway bridge elements. J. Bridge Eng. 2015, 20, 04014060. [CrossRef]

15. Ranjith, S.; Setunge, S.; Gravina, R.; Venkatesan, S. Deterioration prediction of timber bridge elements using the Markov chain. J. Perform. Constr. Facil. 2013, 27, 319-325. [CrossRef]

16. $\mathrm{Ng}$, S.K.; Moses, F. Bridge deterioration modeling using semi-Markov theory. Struct. Saf. Reliab. 1998, 1, 113-120.

17. Mašović, S.; Hajdin, R. Modelling of bridge elements deterioration for Serbian bridge inventory. Struct. Infrastruct. Eng. 2014, 10, 976-987. [CrossRef]

18. Zambon, I.; Vidović, A.; Strauss, A.; Matos, J. Condition Prediction of Existing Concrete Bridges as a Combination of Visual Inspection and Analytical Models of Deterioration. Appl. Sci. 2019, 9, 148. [CrossRef]

19. Fang, Y.; Sun, L. Developing A Semi-Markov Process Model for Bridge Deterioration Prediction in Shanghai. Sustainability 2019, 11, 5524. [CrossRef]

20. Zhang, C.; Zayed, T.; Hammad, A. Resource management of bridge deck rehabilitation: Jacques cartier bridge case study. J. Constr. Eng. Manag. 2008, 134, 311-319. [CrossRef]

21. Washer, G.; Connor, R.; Nasrollahi, M.; Provines, J. New framework for risk-based inspection of highway bridges. J. Bridge Eng. 2016, 21, 04015077. [CrossRef]

22. Ghodoosi, F.; Abu-Samra, S.; Zeynalian, M.; Zayed, T. Maintenance cost optimization for bridge structures using system reliability analysis and genetic algorithms. J. Constr. Eng. Manag. 2017, 144, 04017116. [CrossRef] 
23. Ilbeigi, M.; Ebrahimi Meimand, M. Statistical Forecasting of Bridge Deterioration Conditions. J. Perform. Constr. Facil. 2020, 34, 04019104. [CrossRef]

24. Federal Highway Administration (FHWA). National Bridge Inventory (NBI). 2018. Available online: https://www.fhwa.dot.gov/bridge/nbi.cfm (accessed on 3 May 2020).

25. Ilbeigi, M. An Empirical Markov Process Model for Optimal Bridge Inspection. In Proceedings of the 55th ASC Annual International Conference Proceedings, Denver, CO, USA, 10-12 April 2019; pp. 477-482.

26. Ross, S.M. Introduction to Probability Models; Academic Press: Amsterdam, The Netherlands, 2014.

(C) 2020 by the authors. Licensee MDPI, Basel, Switzerland. This article is an open access article distributed under the terms and conditions of the Creative Commons Attribution (CC BY) license (http://creativecommons.org/licenses/by/4.0/). 